\title{
Characteristics of the Biological Cycle of Lutzomyia evandroi Costa Lima \& Antunes, 1936 (Diptera: Psychodidae) under Experimental Conditions
}

\author{
Maria de Fátima Freire de Melo Ximenes/ ${ }^{+}$, Janaína Cunha Maciel, \\ Selma Maria Bezerra Jerônimo*
}

\begin{abstract}
Departamento de Microbiologia e Parasitologia *Departamento de Bioquímica, Centro de Biociências, Universidade Federal do Rio Grande do Norte, Av. Sen. Salgado Filho s/no, 59078-970 Natal, RN, Brasil
\end{abstract}

Lutzomyia evandroi Costa Lima and Antunes, 1936 is found in Rio Grande do Norte, northeastern Brazil, in areas of visceral and mucocutaneous leishmaniasis and follows the same geographic distribution of L. longipalpis. The biological cycle, oviposition, morphological and behavioral characteristics of the species were studied under experimental conditions. The average number of eggs per wild caught female varied from 21 to 50 eggs along the year, with a peak occurring between January and March and another in August, with oviposition lasting for 4 to 12 days. The mean larval phase was 24 days. Ovipositing rates were influenced by rainfall and temperature indexes, with an increase of eggs per oviposition at the beginning and at the end of the rainy season, and a decrease at the peak of the rainy season.

Key words: Lutzomyia evandroi - oviposition - biological cycle

Lutzomyia evandroi Costa Lima \& Antunes, 1936 is distributed in the states of Ceará, Paraíba, Pernambuco, Maranhão, Minas Gerais, Goiás, and Paraná (Martins et al. 1978, Brazil \& Ryan 1984, Queiroz et al. 1991, Young \& Duncan 1994). Microorganisms including the gregarin Ascocystis chagasi, an unidentified nematode and trypanosomatid (Brazil \& Ryan 1984) were found in the gut of L. evandroi. Study conducted in Jacobina, Bahia, indicated that L. evandroi could be involved in the transmission of Leishmania chagasi to dogs (Sherlock 1996).

In Rio Grande do Norte, northeastern Brazil, L. evandroi is widely distributed and is present in areas of visceral and mucocutaneous leishmaniasis, in both peridomiciliary and intradomiciliary locations. This sand fly has the same geographic distribution as L. longipalpis and is the second most abundant species in the state, representing $11 \%$ of all the sand fly fauna captured (Ximenes et al. 2000). In the peridomiciliary environment, the spe-

\footnotetext{
This research was funded in part by Tropical Medicine Research Center grant from the National Institutes of Health (AI-30639-08) and CNPq (Projeto Nordeste). +Corresponding author. Fax: +55-84 -211.9210. E-mail: ximenes@cb.ufrn.br

Received 27 December 2000

Accepted 14 May 2001
}

cies was found to be more eclectic in its choice of biotopes than L. longipalpis. A comparison of sand flies present in domestic and wild animal shelters revealed that shelters of armadillos and rodents were preferred to horse and chicken shelters. Pregnant and/or engorged $L$. evandroi females possibly use different animals as a source of food and choose more enclosed sites for shelter and rest after copulation and/or feeding (Ximenes et al. 1999).

The population dynamics and ecology of immature stages of sand flies are important components for understanding the abundance pattern of these insects and their relationship with the environment.

The ecology of immature stages of most species is still unknown because of difficulty in locating eggs, larvae or pupae and monitoring their life cycle in natural environment. The detection of immature stages has been rarely reported in natural environments. In Brazil, larvae of L. longipalpis and $L$. oswaldo $i$ were detected in caves, under rocks, at the base of trees, under leaves and under decomposing material in animal shelters (Forattini 1953, Deane \& Deane 1957). In Colombia, the habitats of L. longipalpis and L. trinidadensis larvae were identified using traps for emerging adults (Ferro et al. 1998). L. longipalpis females select ovipositing sites on the basis of the interaction of chemical and behavioral signals (Dia-Eldin et al. 1991, 1992, McCall \& Cameron 1995). Remains of decomposing plant, animal feces and pheromones, present on the surface of the eggs, serve as 
attractants and/or stimulators of oviposition for sand flies reared in the laboratory (Dia-Eldin et al. 1992).

The objective of the present study was to obtain data on the life cycle of $L$. evandroi, including morphological and behavioral characteristics of the immature stages, annual distribution of oviposition, and influence of temperature on ovipositing rates. Those observations are relevant to better understand the ecological factors influencing the development of sand flies. L. evandroi presents similarities of life cycle, behavioral, and has the same geographic distribution of $L$. longipalpis. In addition, L. evandroi is the second most abundant species of Lutzomyia found in Rio Grande do Norte. Finally, further studies are needed in order to define whether L. evandroi can successfully transmit Leishmania to animals as originally suggested by Sherlock (1996).

\section{MATERIALS AND METHODS}

Adult sand flies were captured with light traps (CDC) from February 1997 to January 1998 in the municipality of Nísia Floresta, Rio Grande do Norte. The insects were taken to the laboratory in square cages of nickel-covered wire and nylon netting, measuring $23 \times 23 \mathrm{~cm}$. Males and females were separated and maintained in the laboratory as previously described (Killick-Kendrick et al. 1977, Lawyer et al. 1991, Rowton \& Lawyer 1991). Sand flies were fed a $10 \%$ glucose solution and were allowed to have blood meals on a hamster anesthetized with sodium pentothal $(10 \mathrm{mg} / \mathrm{kg}$ body weight) for $1 \mathrm{~h}$. After three days, females were placed in individual glass flasks covered with a nylon net containing folded filter paper moistened with distilled water. Females were fed by means of a small cotton wool wad soaked in a sugar solution; kept on the top of the net covering the flask, the cotton wads were replaced daily. The flasks were placed in closed plastic boxes over sterilized sand moistened with water in order to maintain humidity at about $90 \%$. The boxes were placed in an incubator (B.O.D. mod. 147 FANEM) at $26^{\circ} \mathrm{C}$ throughout the life cycle.

Eggs were counted and transferred to acrylic pots, internally lined with plaster, three days after oviposition. The immature stages were kept in the plaster pots until the emergence of adult sand flies. The pots were examined daily with the aid of a stereomicroscope to monitor for hatching and development of the immature stages. Larvae were fed with a ration prepared in the laboratory, containing rabbit chow and rabbit feces (1:1) moistened with water and kept at room temperature in plastic trays for about three weeks until overgrown with mold. The ration was then air dried and ground
(Lawyer et al. 1991). All measurements were made with the aid of an ocular micrometer.

The mean number of eggs per wild female captured was calculated monthly.

The effect of temperature on ovipositing behavior were analyzed with females captured in May, June and July 1999. Five groups of 30 females were placed in small flasks closed with nylon netting, fed with sugar and kept in closed plastic boxes with humidity of about $90 \%$, as described above. Each group was kept in an incubator set at a defined temperature of $22,24,26,28$ and $30^{\circ} \mathrm{C}$. Female sand flies were observed daily in order to monitor for ovipositing, and in that occasion dead sand flies were removed from the flasks.

Data were analyzed by analysis of variance using two variables and differing values of $\mathrm{N}$. The Duncan test was used to compare the associations (STATISTICA version 6.0).

\section{RESULTS AND DISCUSSION}

Description of instars development and duration of the life cycle of $L$. evandroi

Pre-ovipositing period - The mean time between the arrival of the females to the laboratory and ovipositing was six days (range: 5 to 9 days) after the blood meal. The differences could reflect an earlier nutrient availability obtained in the field or female age. Females who obtained a blood meal in the laboratory had a longer pre-ovipositing period than the ones that arrived at the laboratory already engorged. Females rarely survived more than $24 \mathrm{~h}$ after ovipositing.

Eggs - The eggs were dark brown in color, elongated and measured about $305 \mu \mathrm{m}$ in length by 98 $\mu \mathrm{m}$ in width. Ovipositing occurred in a clustered manner on the moistened filter paper placed in the flask, probably as a function of its humidity and rugosity, whereas few eggs were collected from the walls of the flask. This phase lasted 4 to 6 days and the mean number of eggs ranged from 21 to 50 .

First and second instar larvae - Newly hatched larvae are very light in color and acquire a yellowish hue as they develop. The first instar $\left(\mathrm{L}_{1}\right)$ is characterized by the presence of a single pair of caudal setae. The second instar $\left(\mathrm{L}_{2}\right)$ has two pairs of setae and measures about $878 \mu \mathrm{m}$ distributed as follows: head, $80 \mu \mathrm{m}$; body, $322 \mu \mathrm{m}$; caudal setae, $476 \mu \mathrm{m}$ $(\mathrm{n}=30)$. The width of the larval body is $80 \mu \mathrm{m}$. The head and caudal lobule are slightly darker in color than the remainder of the body.

Third and fourth instar larvae - These larvae are darker in color than the first and second instars and are considerably larger. In the fourth instar they can measure as much as $2,849 \mu \mathrm{m}$ : the head is 256 $\mu \mathrm{m}$, the body $1,568 \mu \mathrm{m}$, the setae $1,025 \mu \mathrm{m}$, and 
the diameter of the body $300 \mu \mathrm{m}$. The third instar $\left(\mathrm{L}_{3}\right)$ has a larger cephalic capsule than $\mathrm{L}_{2}$, and $\mathrm{L}_{4}$ shows pigmentation of the last segments. $\mathrm{L}_{3}$ and $\mathrm{L}_{4}$ are more active and voracious, requiring a larger amount of food at shorter intervals than the previous instars. The mean duration of the four instars is 24 days (range: 15 to 33 days).

Pupae - After they stop feeding and moving, the pupae, maintaining the exuvium of $\mathrm{L}_{4}$, attach themselves to the wall of the rearing pot by means of the terminal abdominal segment. The pupa measures about 2,400 $\mu \mathrm{m}$ and becomes darker as its cuticle hardens. The pupal period lasts on average 9 days (range: 8 to 10 days).

Adults - The adults are more lightly colored than those of L. longipalpis (light brown), emerge between 8 and 10 days, and have a mean life span of 13 days (range: 11 to 15 days). The males emerge before the females and measure about $1,350 \mu \mathrm{m}$ and $900 \mu \mathrm{m}$, respectively.

The total duration of the life cycle of $L$. evandroi is 51.5 days on average (range: 32 to 54 days) (Fig. 1). Comparison with L. longipalpis showed similar life cycles. However, the larvae of L. evandroi are smaller, lighter in color, move about less, and apparently consume a smaller amount of food than L. longipalpis.

Annual distribution of oviposition - The mean number of eggs per wild caught female oviposition fluctuated along the year, the greatest oviposition occurring between January and March and a second peak occurring in August (Fig. 2). Those differences prooved to be significant $(\mathrm{F}=2.82$ and $\mathrm{p}=0.003$ ). These data suggest that as sand flies keep an ovipositing rate of at least 20 eggs per oviposition along the months, the occurrence of adult specimens throughout the year is guaranteed. It seems that the rate of oviposition is increased when there is a more favorable environmental condition for the development of immature stages.

The number of eggs laid by females captured in March is increased and coincides with the be-

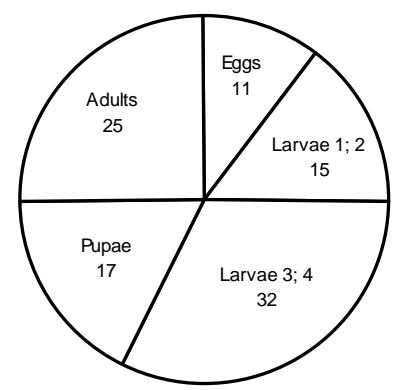

Fig. 1: biological cycle of Lutzomyia evandroi obtained under experimental conditions: average developmental time in days for each stage ginning of rainfall. Contrary to a decrease in number of eggs laid by females captured in May, usually at the peak of rainfall, another increase in the number of eggs is observed for females captured in July and August, which corresponds to the end of the rainy season (Fig. 2). Although there was a fluctuation in the number of eggs laid, those differences were not significant $(\mathrm{p}=0.057)$. These variations may be related to the intensity of rainfall, which might have a deleterious effect on egg and larvae through a direct mechanical action or by a microenvironmental change. In laboratory conditions, immersing the immature stages in water hampered the development of $50 \%$ of the eggs and larvae of $L$. longipalpis (Rangel et al. 1986). Additionally, the increase in soil humidity induced by the rain could contribute to organic substances decomposition in a natural environment and therefore improve the quality of the organic mixture to be used as food by the larvae. The peak of egg production occurring soon after the rainy season might be a strategy adopted by the species to maximize its reproductive rate. On this basis, maximum oviposition occurs in a period when there is humidity necessary for immature stage development in animal shelters, under rocks, inside caves, or in other natural shelters. Scorza and Oviedo (1994), in Venezuela, observed that maximum oviposition (60 or more eggs) occurred during the prepluvial period. Studies of longer duration are needed in order to establish a safe correlation between the different phases of the life cycle and climatic variations. In addition, different blood sources might influence the production of eggs, and therefore studies should be conducted to determine whether animals might influence differentialy the development of sand flies.

Influence of temperature - Fig. 3 shows that $L$. evandroi oviposited at any of the temperatures used, although there was an increase in number of eggs per wild caught female observed at $24^{\circ} \mathrm{C}$. Females that developed in a natural environment

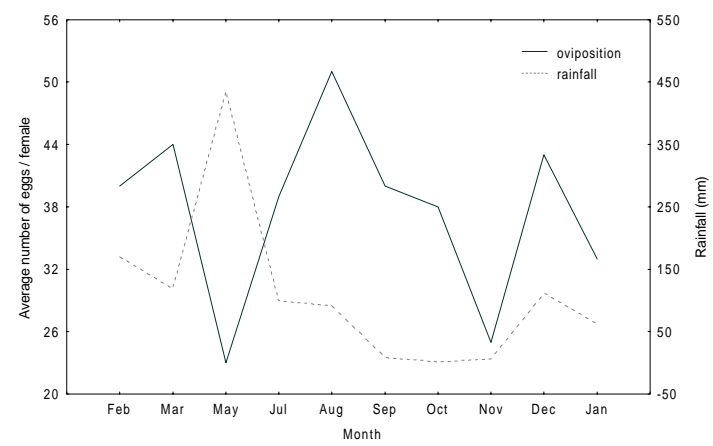

Fig. 2: relationship between Lutzomyia evandroi wild caught female oviposition rates and rainfall regime along the year 
of about $25^{\circ} \mathrm{C}$, showed a mean incubation time of 5 days, when exposed to temperatures of 26,28 or $30^{\circ} \mathrm{C}$. However, if exposed to 22 or $24^{\circ} \mathrm{C}$, there was an increase in the egg incubation, period with a mean period of 12 or 10 days respectively (range: 9 to 18 days). It is known that insects complete their development more rapidly in temperatures around $30^{\circ} \mathrm{C}$. The increase in the mean period of egg incubation might be a mechanism of adaptation and as consequence increases the chance of reproduction when a more appropriate environmental condition exists.

The information obtained by studies using vector colony might contribute to understand vectors involved in disease transmission to humans and other animals, once microenvironmental variables involved in insect growth are better understood and intervene measures can be accurately applied.

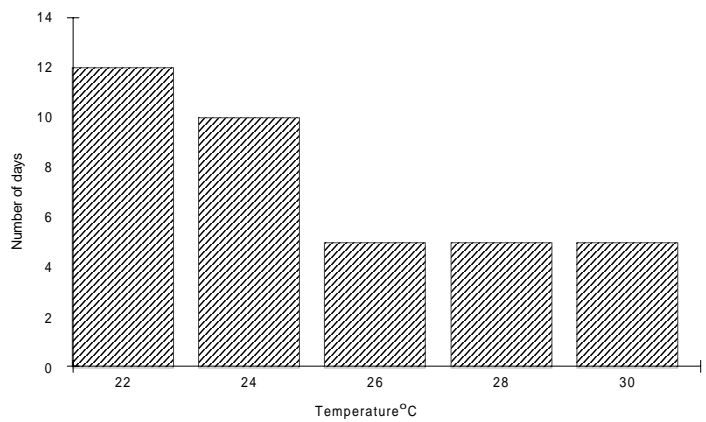

Fig. 3: mean incubation time of Lutzomyia evandroi eggs in different temperatures

\section{ACKNOWLEDGEMENTS}

To Dr Raul Queiroz, Dr Rui Freitas (Instituto Nacional de Pesquisas da Amazônia), Mr Edson Santana (Depto. de Microbiologia e Parasitologia), Joana D'arc Freire (Emparn, RN), and Prof. Domingos Sávio (Estação Climatológica da UFRN).

\section{REFERENCES}

Brazil RP, Ryan L 1984. Nota sobre a infecção de Lutzomyia evandroi (Diptera: Psychodidae) por Ascocystis chagasi (Adler \& Mayrink, 1961) no Estado do Maranhão. Mem Inst Oswaldo Cruz 79: 375-376.

Deane LM, Deane MP 1957. Observações sobre abrigos e criadouros de flebótomos no noroeste do Estado do Ceará. Rev Bras Malariol Doen Trop IX: 225 244.

Dia-Eldin, Elnaiem A, Ward R 1991. Response of the sandfly Lutzomyia longipalpis to an oviposition pheromone associated with conspecific eggs. Med Vet Entomol 5: 87-91.

Dia-Eldin, Elnaiem A, Ward R 1992. Oviposition attractants and stimulants for the sandfly Lutzomyia longipalpis (Diptera:Psychodidae). J Med Ent 29: 5-12.
Ferro C, Cárdenas Estrella, Corredor D, Morales A, Munstermann LE 1998. Life cycle and fecundity of Lutzomyia shannoni (Dyar) (Diptera:Psychodidae). Mem Inst Oswaldo Cruz 93: 195-199.

Forattini OP 1953. Nota sobre criadouros naturais de flebótomos em dependências peridomiciliares no Estado de São Paulo. Arq Fac Hig Saúde Púb 7: $157-167$

Killick-Kendrick R, Leaney AJ, Ready PD 1977. The establishment, maintenance and productivity of a laboratory colony of Lutzomyia longipalpis (Diptera: Psychodidae). J Med Ent 13: 429-440.

Lawyer PG, Rowton ED, Perkins PV, Johnson RN, Young DG 1991. Recent advances in laboratory mass crearing of phlebotomine sand flies. Parassitologia 33: 361-365.

Martins AV, William P, Falcão AL 1978. American Sand Flies (Diptera: Psychodidae: Phlebotominae), Academia Brasileira de Ciências, Rio de janeiro, 195 pp.

McCall PJ, Cameron MM 1995. Oviposition pheromones in insect vectors. Parasitol Today 11: 352355.

Queiroz RG, Vasconcelos I de AB, Sousa RN, Pessoa FAC, Alencar JE, David JR 1991. Phlebotomine sandfly (Diptera: Psychodidae) fauna survey in an American cutaneous leishmaniasis (ACL) focus in Baturité, Ceará State, northeast Brazil. Parassitologia 33(Suppl. 1): 159-167.

Rangel EF, Souza NA, Wermelinger ED, Barbosa AF, Andrade CA 1986. Biologia de Lutzomyia intermedia Lutz \& Neiva, 1912 e Lutzomyia longipalpis Lutz \& Neiva, 1912 (Diptera: Psychodidae), em condições experimentais. 1. Aspectos da alimentação de larvas e adultos. Mem Inst Oswaldo Cruz 81: 431-438.

Rowton ED, Lawyer PG 1991. Advances in sand fly colonization: a summary of workshop discussions at isops1, Rome. Parassitologia 33: 33-37.

Scorza JV, Oviedo M 1994. Physiological age in Lutzomyia young (Diptera:Psychodidae) populations from an endemic area for cutaneous leishmaniasis, Venezuela. Rev Saúde Públ 28: 400-405.

Sherlock IA 1996. Ecological interactions of visceral leishmaniasis in the State of Bahia, Brazil. Mem Inst Oswaldo Cruz 91: 671-683.

Ximenes MFFM, Souza MF, Castellón EG 1999. Density of sand flies (Diptera: Psychodidae) in domestic and wild animal shelters in an area of visceral leishmaniasis in the State of Rio Grande do Norte, Brazil. Mem Inst Oswaldo Cruz 94: 427-432.

Ximenes MFFM, Castellón EG, Souza MF, Freitas RA, Pearson RD, Wilson ME, Jerônimo SMB 2000. Distribution of phlebotomine sand flies (Diptera: Psychodidae) in the State of Rio Grande do Norte, Brazil. J Med Ent 37: 162-169.

Young DG, Duncan MA 1994. Guide to the identification and geographic distribution of Lutzomyia sand flies in Mexico, the West Indies, Central and South America (Diptera: Psychodidae). Memoirs of the American Entomological Institute 54: 881 pp. 